\section{Protecting U.S. temporary waterways}

Protecting the ecological health of rivers relies on maintaining intact flows from source areas to downstream navigable waters (1). Yet, the U.S. Environmental Protection Agency (EPA) intends to rescind legal protection of tributary rivers, streams, and wetlands that do not have yearround flows (temporary waterways) and whose surface waters contribute flow to permanent navigable waters (2). This decision would severely damage the condition and uses of many U.S. waters, both temporary and navigable.

Temporary waterways provide many ecosystem services, including water provision and purification, that contribute substantially to securing water quantity and quality (3-5). Fifty-eight percent of all waterways that provide drinking water to the continental United States are temporary or headwater streams, which support more than one-third of the United States' population (6). Furthermore, temporary waterways harbor important biodiversity (5) and imperiled species (7) and underpin global carbon and nutrient cycles (8). Even when dry, they provide ecosystem services such as providing groundwater, attenuating toxicants, buffering floods, and providing habitat for unique biodiversity $(5,9)$.

A comprehensive scientific review (10) of all the services provided by temporary waterways led to the decision in 2015 to recodify the definition of "waters of the United States" to include temporary waters hydrologically connected to navigable waters. This provided protection to many temporary waterways under the U.S. Clean Water Act, and was hailed as a wise, wellinformed decision (4). However, the recodification has not yet been implemented because the legal process is incomplete, and now reversal of the decision is expected (2).

We urge the EPA to uphold their 2015 decision and to ratify the legal status and protection of temporary waterways. This would provide U.S. temporary waterways with a level of protection similar to that in other countries, such as Australia (5). Failure to do so sets a poor global precedent and, more importantly, risks costly (11) and potentially irreversible harm to the ecosystem services supported by temporary waterways in the United States, including the provision of secure potable water.

Jonathan C. Marshall, ,,2* Vicenç Acuña,"

Daniel C. Allen, ${ }^{4}$ Núria Bonada, ${ }^{5}$ Andrew J.

Boulton, ${ }^{6}$ Stephanie M. Carlson, ${ }^{7}$ Clifford N. Dahm, ${ }^{s}$ Thibault Datry, ${ }^{9}$ Catherine

Leigh, ${ }^{10,11,2}$ Peter Negus, ${ }^{1}$ John $S$. Richardson, ${ }^{12}$ Sergi Sabater, ${ }^{3,13}$ R. Jan Stevenson, ${ }^{14}$ Alisha L. Steward, ${ }^{1,2}$ Rachel Stubbington, ${ }^{15}$ Klement Tockner, ${ }^{16,17}$ Ross

Vander Vorste
${ }^{1}$ Queensland Department of Environment and Science,

Water Planning Ecology, Brisbane, OLD, 4001, Australia. ${ }^{2}$ Australian Rivers Institute, Griffith University, Nathan, QLD, 4111, Australia. ${ }^{3}$ Catalan Institute for Water Research, Girona, Spain.

${ }^{4}$ Department of Biology, University of Oklahoma, Norman, OK 73019, USA. ${ }^{5}$ Grup de Recerca Freshwater Ecology, Hydrology and Management (FEHM-Lab), Departament de Biologia Evolutiva,

Ecologia i Ciències Ambientals, Facultat de Biologia, Institut de Recerca de la Biodiversitat (IRBio),

Universitat de Barcelona (UB), Barcelona, Catalonia, Spain. ${ }^{6}$ School of Environmental and Rural Science,

University of New England, Armidale, NSW, 2350

Australia. ${ }^{7}$ Department of Environmental Science,

Policy, and Management, University of California

Berkeley, Berkeley, CA 94720, USA. ${ }^{8}$ Department of

Biology, University of New Mexico, Albuquerque, NM

87131, USA. 'IRSTEA, UR RiverLy, Centre de Lyon-

Villeurbanne, Villeurbanne, France. ${ }^{10}$ Institute for

Future Environments, and School of Mathematical

Sciences, Queensland University of Technology,

Brisbane, OLD, 4001, Australia. ${ }^{11}$ ARC Centre of

Excellence for Mathematical and Statistical Frontiers,

Queensland University of Technology, Brisbane, QLD, 4001, Australia. ${ }^{12}$ Department of Forest and

Conservation Sciences, University of British Columbia,

Vancouver, BC, Canada. ${ }^{13}$ Institute of Aquatic Ecology,

University of Girona, Girona, Spain. ${ }^{14}$ Center for

Water Science, Michigan State University, East

Lansing, MI 48824, USA. ${ }^{15}$ School of Science and Technology, Nottingham Trent University,

Nottingham, UK. ${ }^{16}$ Leibniz-Institute of Freshwater

Ecology and Inland Fisheries, IGB, Berlin, Germany.

${ }^{17}$ Austrian Science Fund, FWF, Vienna, Austria. "Corresponding author. Email jonathan.marshall@des.qld.gov.au

REFERENCES AND NOTES

1. D. C. Goodrich, W. G. Kepner, L. R. Levick, P. J. Wigington Jr., J. Am. Water Resour. Assoc. 54, 400 (2018).

2. C. Whyte, "Six pollution policies gutted by Scott Pruitt - and what happens next," New Scientist Daily News (2018); www.newscientist.com/article/2173680-six-pollutionpolicies-gutted-by-scott-pruitt-and-what-happens-next.

3. T. L. Nadeau, M. C. Rains, J. Am. Water Resour. Assoc. 43 118 (2007).

4. V. Acuña et al., Science 343, 1080 (2014).

5. T. Datry, N. Bonada, A. Boulton, Eds., Intermittent Rivers and Ephemeral Streams: Ecology and Management (Academic Press, London, 2017).

6. U.S. EPA, "Geographic information systems analysis of the surface drinking water provided by intermittent, ephemeral, and headwater streams in the U.S." (EPA, 2017); www.epa.gov/cwa-404/geographic-information-systems-analysis-surface-drinking-water-provided-intermittent.

7. P. J. Wigington Jr. et al., Front. Ecol. Environ. 4, 513 (2006). 8. T. Datry et al., Nat. Geosci. 11, 497 (2018).

9. A.L. Steward, D. von Schiller, K. Tockner, J.C. Marshall, S.E. Bunn, Front. Ecol. Environ. 10, 202 (2012).

10. U.S. EPA, "Connectivity of streams and wetlands to downstream waters: A review and synthesis of the scientific evidence" (Publication EPA/600/R-14/475F, EPA, 2015).

11. U.S. EPA, "Economic analysis of proposed revised definition of waters of the United States" (EPA, 2014); https://archive.epa.gov/epa/sites/production/files/2014-03/documents/wus_proposed_rule_economic_analysis.pdf.

12. To view or to add to a list of signatories in support of this letter see: https://docs.google.com/document/d/1AS5ew4S3CI3C5TECAmNgi4cu8048BY4WI1AqqIKpog/edit?usp=sharin g.

$10.1126 /$ science.aav0839 